\title{
The pandemic paradox: domestic violence and happiness of women
}

\author{
Wajiha Haq ${ }^{\text {Corresp., } 1}$, Syed Hassan Raza ${ }^{\text {Corresp., } 2}$, Tahir Mahmood ${ }^{3}$ \\ 1 Department of Economics, School of Social Sciences and Humanities, National University of Science and Technology, Islamabad, Pakistan \\ 2 School of Economics, Quaid-i-Azam University, Islamabad, Pakistan \\ 3 Department of Technology, School of Science and Technology, Open University of Hong Kong, Kowloon, Hong Kong \\ Corresponding Authors: Wajiha Haq, Syed Hassan Raza \\ Email address: dr.wajihahaq@s3h.nust.edu.pk, shraza@qau.edu.pk
}

Background. Across the globe, lockdowns have been enforced as a pandemic response to COVID-19. Such lockdown coupled with school closures and stay-at-home orders made women more vulnerable in terms of higher responsibility and spending more time with an abusive partner if any.

Methods. This study investigates the situation of women during COVID-19 induced lockdown by focusing on their happiness and inquiring about the incidence of violence. Using the zero-inflated negative binomial model, our findings ascertained that family settings, type of relationship with a spouse, and age significantly affects the positive count of violence during the lockdown. We further estimated the determinants of happiness and found that years of schooling, the role of women in household decision making, and feeling empowered is affecting their happiness.

Results. Women having higher education have more odds of zero violence. Unemployed women and women who are not working have higher odds of zero violence as compared to the working woman. During this lockdown after the COVID-19 pandemic, women living in urban areas, having higher education, having an adequate household income to meet the expenditures, having lesser anxiety, not facing violence, feeling empowered when their husband is around, and have higher decision-making power are happier.

Discussion and conclusion. The study is important in the context of happiness and violence inflicted on women during the lockdown and provides the basis to improve the pandemic response policy. The inclusion of women's safety and happiness in pandemic response policy is important to ensure the wellbeing of women and to devise better health and economic policy. Our estimates suggest higher education results in less incidence of violence which could be argued as desirable outcomes for building healthy, productive, and happy communities. In addition to this, as pandemic induced lock-down is likely to result in higher unemployment across the globe including Pakistan, therefore, in light of our estimates pertaining to the role of unemployment in the incidence of violence, policymakers should deploy more resources to enhance income and to combat the rising unemployment. As a counter-intuitive outcome of these policy interventions incidence of violence will be dampened, educational attainment and women empowerment will be increased which will certainly increase happiness. 


\section{The Pandemic Paradox: Domestic Violence and}

\section{Happiness of Women}

3

4 Wajiha Haq ${ }^{1}$, Syed Hassan Raza ${ }^{2}$, Tahir Mahmood

5

6 Science and Technology (NUST), Islamabad, Pakistan. Kong, Kowloon, Hong Kong.

Corresponding author:

Wajiha Haq, Ph.D ${ }^{1}$

Department of Economics, School of Social Sciences and Humanities, National University of Sciences and Technology (NUST), H-12, Islamabad, 44000, Pakistan Email: dr.wajihahaq@s3h.nust.edu.pk

Co-Corresponding author: Syed Hassan Raza, Ph.D ${ }^{2}$

School of Economics, Quaid-i-Azam University, Islamabad, 44000, Pakistan Email: shraza@gau.edu.pk

\section{Abstract} if any.

${ }^{1}$ Department of Economics, School of Social Sciences and Humanities, National University of

${ }^{2}$ School of Economics, Quaid-i-Azam University, Islamabad, Pakistan.

${ }^{3}$ Department of Technology, School of Science and Technology, Open University of Hong

Background. Across the globe, lockdowns have been enforced as a pandemic response to COVID-19. Such lockdown coupled with school closures and stay-at-home orders made women more vulnerable in terms of higher responsibility and spending more time with an abusive partner

Methods. This study investigates the situation of women during COVID-19 induced lockdown by focusing on their happiness and inquiring about the incidence of violence. Using the zero-inflated negative binomial model, our findings ascertained that family settings, type of relationship with a spouse, and age significantly affects the positive count of violence during the lockdown. We 
further estimated the determinants of happiness and found that years of schooling, the role of women in household decision making, and feeling empowered is affecting their happiness.

Results. Women having higher education have more odds of zero violence. Unemployed women and women who are not working have higher odds of zero violence as compared to the working woman. During this lockdown after the COVID-19 pandemic, women living in urban areas, having higher education, having an adequate household income to meet the expenditures, having lesser anxiety, not facing violence, feeling empowered when their husband is around, and have higher decision-making power are happier.

Discussion and conclusion. The study is important in the context of happiness and violence inflicted on women during the lockdown and provides the basis to improve the pandemic response policy. The inclusion of women's safety and happiness in pandemic response policy is important to ensure the well-being of women and to devise better health and economic policy. Our estimates suggest higher education results in less incidence of violence which could be argued as desirable outcomes for building healthy, productive, and happy communities. In addition to this, as pandemic induced lock-down is likely to result in higher unemployment across the globe including Pakistan, therefore, in light of our estimates pertaining to the role of unemployment in the incidence of violence, policymakers should deploy more resources to enhance income and to combat the rising unemployment. As a counter-intuitive outcome of these policy interventions incidence of violence will be dampened, educational attainment and women empowerment will be increased which will certainly increase happiness.

\section{Introduction}

The world is facing the pandemic of COVID-19, which is the greatest global health crisis of our time. The pandemic is affecting people across all the age groups, gender, or ethnicities which exacerbates the psychological, social, and economic repercussions. The pandemic induced lockdown has exposed the underlying vulnerabilities of women as they are forced to stay at home, work from home, and implement social distancing. This situation reduces women's autonomy especially in patriarchal homes which is also evident from the increase in incidents of domestic violence incidents across the globe (Peterman et al. 2020). Therefore, it is noteworthy to document whether the COVID-19 is a double pandemic for women or not in a context? If she goes out, she is vulnerable, but the question remains for her safety if she stays at home. Besides, it is also imperative to 
71 capture the extent of her happiness while staying at home. Such an assessment is pivotal 72 to devise better and effective economic, health, and social welfare policy.

73 The COVID-19 made women vulnerable to all sorts of gender-based violence. The rates 74 of violence against women increased across the globe during the pandemic (Pfitzner et 75 al. 2020; Ravindran \& Shah 2020). The COVID-19 pandemic and accompanying increase 76 increased exponentially (United Nations Office on Drugs and Crime 2020).

Of note, the World Bank (2020) also called to investigate the impact of COVID-19 induced lockdown on the women given the issues related to empowerment, happiness, and violence against women.

In Pakistan, as of May $30^{\text {th }}, 22.48 \%$ of women have been infected by the COVID-19 with the highest prevalence rate among the age group of 20 to 29 years (OCHA Pakistan 2020). Apparently, women seem less infected by the pandemic as higher mortality is observed among men due to more prevalence of smoking and gender-based immunological differences (Wenham et al. 2020). Governments across the globe have implemented lockdowns, enforced people to stay at home and work from home, and further announced the complete closure of educational and non-educational institutes. Due to culturally imposed roles of women and patriarchal norms in many countries, the wellbeing of women is adversely affected as they are at the forefront as unpaid caregivers or front line workers even during the pandemic (Gibbs et al. 2020). The domain of adverse effects on women is broad, which primarily includes the risk of violence, ill-being, and adverse psychological health. Furthermore, it has been widely argued that the effects of economic slow-down bring more severe consequences to women compared to men in the context of job security and wage differences (de Paz et al. 2020). Even the wellbeing of unpaid caregivers (housewives) is influenced through the instability in the economic outcomes of households along with various other sociological and psychological outcomes. On the face of the outcomes, the vulnerability of women during the COVID19 induced lockdown becomes an even more important phenomenon to capture. 
101 As of May 30, 2020, the majority of the countries including Pakistan are still under some 102 form of partial or complete lockdown. Thus, it could be argued that the economic turmoil 103 induced by lockdown coupled with restrictions on mobility and social isolation may expose 104 women to domestic violence. In particular to Pakistan, on an average basis, one in four 105 women suffers from emotional, physical, or sexual violence (PDHS, 2019). This implies 106 that at least eight million women grapple with various forms of violence every year and 107 Pakistan is already argued as the sixth most dangerous country for the women (Thomson 108 Reuters Foundation 2018). As a social norm, the majority of the women in Pakistan are 109 not particularly active in the labor market; thus, staying home and performing daily 110 household chores are their routine but a significant number goes to work for daily 111 livelihood. Under such circumstances, whether working or not, when the government has 112 induced lock-down staying at home with an abusive partner during the COVID-19 induced 113 lockdown makes them more vulnerable, and this certainly affects their wellbeing as well.

114 Safdar \& Yasmin Alvi (2020) argued, "the chances of the vulnerability of the negotiated 115 identity and social space of middle-class educated Muslim women in urban Pakistan get heightened in situations like COVID-19 mainly due to the religiously inspired dominant 117 patriarchal social behaviors and the state's inability to practically empower its women 118 during normal conditions".

119 Those women who are already marginalized with limited economic resources, 120 overburdened household responsibilities, and taking care of children are more 121 susceptible to violence while spending more time with an abusive partner during the 122 COVID-19 induced lockdown with dismal support (United National, 2020). This sort of 123 lockdown situation dampens their ability to look for other alternatives and results in 124 accepting the violence with lower happiness.

125 It is noteworthy that under varied circumstances, women not only accept the violence but 126 considers it normal (Garcia et al., 2005). Women mostly work in the informal sector and 127 are excluded from formal social insurance and protection especially in the developing 128 world (de Paz et al. 2020). Besides, the responsibility of taking care of children and older people also falls on her shoulders. United Nations (2020) in its policy brief about the impact of COVID-19 on women mention that on average, women spend $4.1 \mathrm{hrs} / \mathrm{day}$ on unpaid work including domestic chores and care provision compared to $1.7 \mathrm{hrs} /$ day by 
132 men. As far as unpaid contributions from women are concerned, they constitute $2.35 \%$ of 133 the total GDP. Across all the age groups, women take care of the elderly. Therefore, they 134 are considered as one of the most important pillars of healthcare. Past outbreaks have 135 shown that promoting gender roles increase the efficacy of health interventions (Wenham 136 et al. 2020). At the intersection of above-mentioned ideas and debates, it is pivotal to 137 capture the violence and happiness of the women during the COVID-19 induced 138 lockdown in Pakistan so that an effective pandemic response including women, ensuring 139 their safety and wellbeing, can be devised and they can play an active and effective role 140 in the fight against COVID-19.

\section{Materials \& Methods}

\section{QUESTIONNAIRE DESIGN}

143 To investigate the situation of women during the lockdown in this pandemic, a survey is 144 designed based on literature (de Paz et al. 2020; Ewerling et al. 2017; UNHCR-IDC 2016; 145 World Bank 2020; Zhang et al. 2020) for married women. Our survey has gone through various checks, including a detailed discussion on the design of the survey and ethical standards by the experts. The National University of Science and Technology, Pakistan granted ethical approval for the study (Ethical approval Letter Ref: 0801/02/fac-offr/s3h). Participants were informed about the purpose of the questionnaire that they are going to be filled and the anonymity of respondents was assured. In addition to this, we did not ask any personal details such as name, address, contact or national identity number. Filling out the questionnaire and submitting it was their informed consent. Furthermore, we initially launched the pilot survey in the last week of May 2020, and later, after the necessary corrections, we fielded the survey in the first three weeks of June 2020. The main intent of the survey remains about documenting the responses of such women who are tech aware to fill up the survey. Although we understand in this situation we will have a majority of the responses from the women who are truly educated to use the technology. Nonetheless, if they are facing a double pandemic including COVID-19, lockdown induced violence, and loss of happiness so our findings remain applicable to those who are not really tech aware and perhaps not too educated as well due to the overall dismal situation of Pakistan in terms of gender parity and violence against women. The overall indicators for violence against women are in jeopardy. According to (United Nations Office 
163 on Drugs and Crime 2020), 90 percent of women in Pakistan have faced some form of 164 domestic violence. Our study, although based on technologically advanced women, also 165 has implications for women who are not technologically advanced as they will certainly 166 be at least in the same situation or worse than this.

167 We rely on snowball sampling and conducted the online survey because face to face 168 interviews are not possible due to the ongoing lockdown situation, therefore, focusing on such women which are tech aware and able to fill the online survey serves the need. Google forms are used to make the online survey and respondents are shared the link to fill the questionnaire.

172 The survey covered the demographic, economic, socioeconomic, and psychological 173 aspects of married women. In addition to this, the respondents are asked to provide 174 information on the technological awareness, relationship with husband, self-perceived 175 empowerment, role in household decision making, violence, and happiness during the 176 COVID-19 induced lockdown. Demographic variables of married women include region 177 (urban/rural), age (years), education (years of education), employment status (full time working, part-time working, not working and unemployed), her husband's age, husband years of education, husband's employment status, amount of her salary, and the number of children. Women were also asked about the kind of family setting they live in, which includes nuclear family, extended family, and multiple family settings. The nuclear family was operationally defined as the family which includes husband, wife, and children. The extended family was operationally defined as a family having a husband, wife, children, grandchildren, their parents, and any unmarried siblings living together in the same house. Multiple families were operationally defined as the family having husband, wife, children, grandchildren, their parents, parents-in-law, married siblings, and their children living together in the same house.

Women were also asked to rate their relationship with their husbands on a Likert scale ranging between very poor (coded as 1 ) and very good (coded as 5 ). Women's perception regarding their empowerment was also captured before and after the pandemic. They were asked about how much they feel that they were empowered before COVID-19 to which they responded on a seven-point scale ranging between not very empowered to very empowered. The respondents also provided the information whether they feel 
194 empowered when their husband is around to which they responded using a Likert scale 195 ranging between strongly disagree to strongly agree. The psychological effect of the 196 pandemic on women was also investigated by asking women about having anxiety after 197 the pandemic. The same five-point Likert scale of the agreement was used to get the 198 responses.

199 Sufficiency of household income during COVID-19 related lockdown, access to the police 200 for seeking help during the violence, and access to personal protection equipment (hand 201 gloves, face masks, and hand sanitizers) were also asked. During the lockdown, women 202 are in trouble because all the responsibility falls on their shoulders. School closures have 203 also brought extra responsibility of teaching children at home to her. In this context, 204 women were asked that do they take care of children alone, with a husband or husband 205 takes care of them, or she seeks the help of someone else. The same question was 206 rephrased for performing household chores in order to see who is mainly responsible for 207 taking care of children and performing household chores.

208 Women's decision making was captured through three dimensions. Their decision making 209 in economic matters, health spending, and social distancing captured through a five-point 210 Likert scale was used to construct the variable. Access to personal protection equipment 211 was measured through three items, namely access to hand gloves, face mask, and hand 212 sanitizers which were responded with Yes/No. The reliability of items to measure the 213 variables was checked through Cronbach Alpha. The Cronbach Alpha of women's 214 decision making was 0.75 , and access to personal protection equipment was 0.78 . The 215 The Cronbach alpha of violence is 0.8 . Following the reliability criteria Bland \& Altman 216 (1997), the items were valid to measure the phenomena as their values lied between $2170.70-0.90$. We can say that the instrument used to measure the phenomenon is valid 218 (Wang et al. 2020) and generalized with a 5\% chance of error. Since the main focus of 219 the survey is to capture the dynamics related to COVID-19 induced lockdown in the 220 context of violence, empowerment, and happiness of the women, thus, the measurement 221 of violence and happiness is explained as follows.

222 Women violence: Violence is a worldwide phenomenon, and during this 223 lockdown, World Health Organization along with many other researchers have shown the 224 concern that the prevalence of women violence may increase during this lockdown 
225 (Peterman et al. 2020; Safdar \& Yasmin Alvi 2020; United Nations 2020; World Bank 226 2020). Since the phenomena of violence may take various forms such as physical, 227 emotional, and verbal abuse. The definition of violence was derived from the literature 228 (World Health Organization 2005). Thus, we asked the count (i.e. the number of times) 229 the respondent (married women) faced any violence (physical, emotional, and verbal) 230 during this lockdown. In addition to this, we further asked her (Yes/No) if she experienced a similar type of violence before such a lockdown. We are particularly interested to know what is happening with her during the lockdown but it is important to understand if the 233 similar situation prevailed before the lockdown.

The overall happiness of women: COVID-19 has not only affected people with disease directly but also affected their mental health indirectly. Their indirect effects are far more than the direct effects. The pandemic has affected the mental health of people including women because of boredom, frustration, and fear of getting the disease (Brooks et al. 2020). In addition to this, as we discussed earlier that women are at increased risk of violence during the pandemic induced lockdown, thus, it is right to argue that it can definitely effect the subjective happiness of those women. As happiness comes from stronger and healthier relationships with friends, families, and partners in addition to other sources (Diener \& Seligman 2002) whereas poor social relationships have a negative impact on happiness. An empirical study in Nicaragua investigated that women having episodes of abuse are not very happy (Vázquez et al., 2015)"

The respondents were asked that overall, how much they feel happy about their life before and after the pandemic which we operationally defined as overall subjective happiness. A seven-point scale was used to gauge happiness (Chinni 2014) which ranges from not very happy (coded as 1) to very happy (coded as 7).

\section{DATA COLLECTION}

250

251

252

253

254 255

The data was collected through a snowball sampling technique where the questionnaire was floated among few married women, and they were asked to share this questionnaire with other married women they know as well. The mode of data collection was online to ensure safety and to avoid any inconvenience for the respondents during the lockdown. Through online data collection, we also did not breach the standard operating procedures of social distancing advised by the Government of Pakistan. During this situation, the best 
256 possible way to collect data is through the online surveying approach(Wang et al. 2020). 257 The online data collection helped us to spread our reach to married women across 258 Pakistan. We collected the data from 412 married women, and after the necessary data 259 cleaning for missing observations, we retained 389 responses. Therefore, with a $3 \%$ 260 margin of error and a 95\% confidence level, our data is a national representative. Women 261 in our sample belong to 54 distinct districts of Pakistan which prove that the regional 262 variation is significantly covered in our survey.

263

264

265

266

267

268

269

270

271

272

273

274

275

276

277

278

279

280

281

282

283

\section{ANALYSIS TECHNIQUE}

The zero-inflated Negative Binomial model: The data of violence is collected in the form of the number of violence during the lockdown, where most of the women reported no violence (i.e., zero counts). There exist several discrete distributions to model count data such as Poisson, Negative Binomial, zero-inflated Poisson (ZIP), and zeroinflated Negative Binomial (ZINB) distribution. For the modeling, the first step is to know the best-fitted distribution of the dependent variable, and for such purpose, we have fitted all competitive count distributions, and computed their results. Based on the results, an excess number of zeros and over-dispersion, we reached to the conclusion that zeroinflated negative binomial (ZINB) is the best-fitted distribution to model the number of violence. Due to the excess number of zeros and over-dispersion, we assessed that the ZINB distribution is the best-fitted model for the violence (see results section). The ZINB distribution comprises two processes, where one is used to model the nonzero counts (i.e., $y>0$ ) while the other is used to fit the zero counts (i.e., $y=0$ ). Hence, the probability mass function of the ZINB can be described as follows:

$$
f(y ; p, \lambda, \tau)=\left\{\begin{array}{cc}
(1-p)+p \times\left(\frac{\tau}{\tau+\lambda}\right)^{\tau} & y=0 \\
p \times \frac{\Gamma(y+\tau)}{y ! \Gamma(\tau)}\left(\frac{\tau}{\tau+\lambda}\right)^{\tau}\left(\frac{\lambda}{\tau+\lambda}\right)^{y} & y=1,2, \ldots,
\end{array},\right.
$$

where $\lambda$ is the mean of the underlying Negative Binomial distribution, $\tau$ is the overdispersion parameter and $p$ is the probability of zero observations. It is to be noted that when $\tau \rightarrow 0$, the ZINB model reduced to the ZIP distribution, when $p \rightarrow 0$, the ZINB model reduced to the Negative Binomial distribution, and when both $1 / \tau$ and $P_{i} \approx 0$ the ZINB distribution also reduced to the ordinary Poisson distribution. 
284 In order to see the factors affecting the violence on women during this lockdown, the ZINB 285 regression is used to model the data. The ZINB regression model is defined as follows:

286

$$
P\left(Y_{i}=y_{i} \mid X_{i}, Z_{i}\right)=\left\{\begin{array}{cc}
\left(1-p_{i}\right)+p_{i} \times\left(\frac{\tau}{\tau+\lambda_{i}}\right)^{\tau} & y_{i}=0 \\
p_{i} \times \frac{\Gamma\left(y_{i}+\tau\right)}{y_{i} ! \Gamma(\tau)}\left(\frac{\tau}{\tau+\lambda_{i}}\right)^{\tau}\left(\frac{\lambda_{i}}{\tau+\lambda_{i}}\right)^{y} & y_{i}=1,2, \ldots,
\end{array},\right.
$$

287

288

289

290

291

292

293

294

295

296

297

where the vectors $X_{i}^{\prime}=x_{i, 0}, x_{i, 1}, \ldots, x_{i, m}$ contains $m$ covariates and $\beta^{\prime}=\left(\beta_{0}, \beta_{1}, \ldots, \beta_{m}\right)$ is the vector of $m$ unknown parameters. However, the vector $Z_{i}^{\prime}=z_{i, 0}, z_{i, 1}, \ldots, z_{i, m}$ contains $m$ covariates for defining the probability of excess zero $P_{i}$ and $\gamma^{\prime}=\left(\gamma_{0}, \gamma_{1}, \ldots, \gamma_{m}\right)$ is the vector of $m$ unknown parameters. The ZINB log-likelihood given the observed data is obtained as follows:

$l(Y, \beta, \gamma, \tau)$

$=\sum_{i=1}^{n} \ln \left(1+e^{Z_{i}^{\prime} \gamma}\right)-\sum_{i: y_{i}=0} \ln \left(e^{Z_{i}^{\prime} \gamma}+\left(\frac{e^{X_{i}^{\prime} \beta}+\tau}{\tau}\right)-\tau\right)+\sum_{i: y_{i}>0} \ln \left(\tau\left(\frac{e^{X_{i}^{\prime} \beta}+\tau}{\tau}\right)+y_{i} \ln \left(1+e^{X_{i}^{\prime} \beta} \tau\right)\right)$

$+\sum_{i: y_{i}>0} \ln (\Gamma(\tau))+\ln \left(\Gamma\left(1+y_{i}\right)\right)-\ln \left(\Gamma\left(\tau+y_{i}\right)\right)$,

298

300

301

302

303

304

305

and the estimates of ZINB regression model are obtained by solving the log-likelihood using the iterative BFGS method (for more details on iterative BFGS method, see Fletcher (2013))

The Multinomial logistic model: To see the effect of potential factors affecting the happiness of women after COVID-19, we have used multinomial logistic regression as the dependent variable was categorical. We also tested the assumption of parallel lines which confirmed the use of said technique and justified its preference over ordinal regression. 
306

307

308

309

310

311

312

313

314

315

316

317

318

319

320

321

322

323

324

325

326

327

328

329

330

331

332

333

334

335

336

337

338

339

340

$\theta\left(Y=k \mid X=x_{m i}\right)=\operatorname{logit} \delta(x)=\ln \left[\frac{\delta(x)}{1-\delta(x)}\right]=\beta_{o k}+\beta_{1 k} x_{1 i}+\beta_{2 k} x_{2 i}+\beta_{3 k} x_{3 i}+\ldots+\beta_{n k} x_{n i}$.

Where " $Y$ " is a vector for dependant variable having $k$ outcomes and " $X$ " is a vector for independent variables. The number of observations is given by " $i$ " and " $m$ " denotes the number of independent variables.

\section{Results}

In our sample, on an average basis, women are married for around 14 years. The average age of our respondents (women) is 38 years ranging between 20 to 72 years. As far as the number of children is concerned, $47 \%$ of women in our data have 2 children. It is interesting to note that in our survey, the majority of the women are highly educated, as we document on an average basis women have 14 years of schooling and their husbands have 15 years of schooling. Perhaps the logical reasoning behind this number is an online survey; nonetheless, it provides an interesting insight into the mentioned phenomena. As mentioned earlier we are particularly interested to capture the dynamics for such a woman who is tech aware and can fill the online survey. Although, the generalizability of our research remains intact for those who cannot use technology or perhaps more domesticated women even if there is a limit to generalizability we are more interested here to identify the issue of violence and happiness for the particular groups of women who are able to use the technology to fill up the survey. The mean education of women's fathers' education is higher secondary school certification and for women's mothers' education is graduation. The years of schooling shows the level of education attained. In Pakistan, 10 years of schooling is equivalent to secondary school certification, 12 years of schooling is equivalent to higher secondary school certification, 16 years of schooling is equivalent to graduation, 18 years of schooling is equivalent to post-graduation and 22 years of schooling is equivalent to a doctorate. For the respondent's earnings, we observe that around $27 \%$ of the women in the sample earn more than PKR 25,000. For living arrangements, we observe that around $25 \%$ of women live in an extended family, and $12 \%$ of women live in multiple family settings. To observe the geographic variation, we see $17 \%$ of women belong to rural areas. Table 1 presents a detailed summary statistic of the few demographic variables. Additionally, we observe from the data based on literature that there is significant rise in the number of women who reported such a violence (including physical, emotional and verbal) during lockdown. After the lockdown was announced, the incidence of women violence has increased exponentially (United Nations Women 2020; Warraich 2020). Therefore, we have a strong case here to observe what has caused the violence during the COVID-19 induced lockdown. a

[Insert Table 1 here]

Peer) reviewing PDF | (2020:09:52535:2:0:NEW 8 Nov 2020) 
341 VIOLENCE ON WOMEN DURING COVID-19 RELATED LOCKDOWN

342 In our sample, our calculations revealed that $65 \%$ of women $(\mathrm{N}=257)$ have reported that 343 they have not faced any violence during this lockdown, but the rest of the $35 \%(\mathrm{~N}=132)$

344 revealed to suffer from some form of violence during the lockdown, and this primarily 345 includes physical, emotional and verbal violence. In particular to physical violence, 83\% 346 of women no violence at all, but the remaining $17 \%$ reported having faced emotional 347 violence up to 12 times during this lockdown. It is noteworthy that it has been three months 348 since the Government has imposed the lockdown. The number of times women faced 349 verbal and emotional abuse is higher than physical violence. Around $28 \%$ of women faced 350 verbal violence, and $34 \%$ of women faced emotional violence. Verbal and psychological violence both contribute towards emotional violence where the women are not physically beaten but yet bruised mentally. According to WHO, emotional abuse is also part of intimate violence which is hurtful and usually not focused. Violent men use a range of strategies to exercise their power and control, which also includes emotional violence (García-Moreno et al. 2005). When a man cannot demonstrate himself as a successful man as expected by society, then he suffers from an identity crisis and uses violence to solve that crisis. (Peterman et al. 2020). It is important to see the factors which are increasing the violence on women during the lockdown.

In this study, the number of violence is defined as the number of times a woman faced violence (i.e., physical/emotional/verbal). We applied Poisson, Negative Binomial, ZIP, and ZINB distributions to access the best-fitted count model for the number of violence. By following the goodness of fit criterions such as log-likelihood, Akaike Information Criterion (AIC), and Bayesian Information Criterion (BIC), which are reported in Table 2, we found that the number of violence is best fitted using the ZINB distribution as it showed 365 minimum values of log-likelihood, AIC and BIC as compared to other models.

Further, to access the influential factors that affect the number of violence, the ZINB 368 regression was applied, and the findings of the ZINB model are reported in Table 3. We found that age significantly affects the violence count, but the odds of elderly women having more frequency of violence are very less. This could be argued as the longevity 
372 violence which even stays significant during the lockdown situation. The family setting in 373 which a woman lives also plays an important role in violence where a woman can face 374 more burden of responsibilities, strict enforcement of her assumed roles decided by the 375 patriarchal system, and stereotyping. As compared to an extended family where a woman 376 lives, the odds of having a higher frequency of violence are lesser in a nuclear family and 377 multiple families. Around $25 \%$ of women in the sample live in an extended family setting 378 and are more vulnerable to violence during this COVID-19 related lockdown. Around $42 \%$ 379 of women reported taking care of children alone, and $55 \%$ of women perform household 380 chores on their own.

382 For zero violence, urban areas as compared to rural areas have more odds of having 383 definite zero violence. Women having higher education have more odds of zero violence. Unemployed women and women who are not working have higher odds of zero violence as compared to the working woman. These women also have higher odds of having a higher frequency of violence.

As compared to women who are working, unemployed women and not working women have higher odds of having violence. It demonstrates that financial independence coming in complement with working plays an important role in avoiding violence. Additionally, we found the role of relationship women shares with her spouse plays a pivotal role in determining the violence. For instance, those women who have reported a very good relationship with their husbands as compared to very poor have lower odds of having violence during the lockdown. Working women during the lockdown faced a lot of trouble to fit in stereotypical roles, perform equally well in the job and managing housekeeping everyone safe. The struggle was hard for working women as compared to women who are not working or unemployed because they had the double burden of workplace and house management without house help. Her employment status may become a factor for her higher odds of violence. If everything is fine, unemployed and women who are not 399 working will be not facing any violence, but they may also have higher odds of having a 400 higher frequency of violence as compared to working women if things at her home or with 401 her husband are not smooth. 
402 This implies the role of anxiety in determining the violence, and this has been ascertained 403 with the use of ZINB regression along with the count. Anxiety is also an important factor 404 to affect violence. An anxious woman may involve in fight rejecting the patriarchal roles 405 or asking the husband for helping her in responsibilities. She might not appear as a perfect 406 and happy servant for the house all the time because of her own disturbed mental health 407 and anxiety due to COVID-19. Women who do not have anxiety have higher odds of 408 having zero violence. As compared to agreeing, if she disagrees with having anxiety, then 409 still the odds of having violence are positive.

410 Empowerment of women is also important to reduce violence against them (World Health 411 Organization 2005). Women who were very empowered before COVID-19 as compared 412 to those who were not very empowered have higher odds of having violence. The results 413 seem surprising, but in the Pakistani context, they are not. Since very empowered women 414 who were working (most probably) and taking decisions independently before the COVID41519 lockdown is now facing difficulty in accepting the stereotyping and taking care of 416 children alone (after school closures) and without house help. This suggests that she is 417 struggling to involve her husband in every responsibility and to shun the patriarchal 418 norms. In this struggle, she has higher odds of facing violence. Women empowerment is 419 often complimented with her role in household decision making. Therefore, we analyzed 420 that as compared to those women who strongly disagree that they have "any say in social 421 distancing", women with more "say" have lower odds of having violence. As their 422 autonomy in social distancing decision increase, the odds of having violence decreases. 423 Childcare is a very important responsibility during this lockdown, especially when the 424 orders for daycare closures and school closures are already in place. If a woman is 425 performing this duty alone or others (for example relatives, woman's parents, husband's 426 parents are doing it), then odds for a woman facing violence are higher as in both cases 427 the husband's involvement is zero which may become the cause of dispute. At the same 428 time, if a woman is agreeing on feeling empowered when her husband is around, her 429 odds of having violence is lower.

430 We investigated that the region, age, education, employment status, and anxiety are 431 significantly affecting and predicting zero violence. In count model, we found that age, 432 type of family setting, type of relationship with husband, feeling empowered before 
433 COVID-19, childcare responsibility, anxiety, and feeling empowered when the husband is 434 around are important factors that affect the frequency of violence that women face. Living 435 urban/rural regions, education of woman/ husband, number of children, and adequacy of 436 household income during this lockdown does not affect the count of women's violence.

437 THE OVERALL HAPPINESS OF WOMEN AFTER COVID-19 RELATED LOCKDOWN 438 The overall happiness of women after COVID-19 related lockdown is found to be affected 439 by many factors. The assumption of parallel lines was checked to fit ordinal models, but 440 a violation of it suggested the use of multinomial logistic regression. The results are 441 detailed in Table 4.

442

443

444

445

446

447

448

449

450

451

452

453

454

455

456

457

458

459

460

461

462

463

\section{[Insert Table 4 here]}

Using this technique, we found that women living in urban areas have higher odds of being happy than a woman living in a rural area during the lockdown period. Women locked down at home in urban areas have more access to utilities, facilities and have formal jobs which may make them happier. Age is significant to affect the happiness of women, but the odds are close to 1 . Women having higher education have more odds of being happier than not very happy. Women living in nuclear family settings have higher odds of being overall happier than being not very happy. If the women strongly agree that household income is adequate for household expenditures, the odds of her being happy are higher. This implies the role of economic factors in determining happiness during the COVID-19 induced lockdown. If a woman agrees to have anxiety, then she has lower odds of being happier. Similarly, if she has emotional violence, then the odds of her being very happy are less. Since the happiness and psychological/emotional health are closely interrelated, thus, this finding further ascertains this phenomenon. If the woman's role in decision making is more, then her odds of being happier are high. If the woman disagrees with feeling empowered when her husband is around, then her odds of being happier are significantly less. If a woman disagrees to feel empowered, then her odds of being happier are less.

During this lockdown after the COVID-19 pandemic, women living in urban areas, having higher education, having adequate household income to meet the expenditures, having lesser anxiety, not facing violence, feeling empowered when their husband is around, and have higher decision-making power are happier.

Peer) reviewing PDF | (2020:09:52535:2:0:NEW 8 Nov 2020) 


\section{Discussion and Conclusion}

465 Following WHO concerns of increased vulnerability of women amid the pandemic and 466 calling for explaining the situation of women in specific contexts, we used the survey to 467 investigate the situation of married women in Pakistan. Women staying at home are not 468 safe, rather they are facing violence. They have higher odds of facing violence if they are locked down in an extended family setting, having higher number of children and having bad relationship with husband. The odds are also higher for unemployed women and those who are not working. If they are having anxiety, taking care of children alone and do not feel empowered if their husband is around then the odds of facing violence for women are higher. She is more enrooted in her patriarchal role assumed by society, and she has been endorsed firmly than ever. She is overburdened, anxious, and facing violence. In the $21^{\text {st }}$ century and digital age, married women living in Pakistan are still not safe at homes where they are isolating themselves to avoid the disease.

Yet, the prevalence of violence does not mean that every woman is facing physical violence, so we also asked the woman about their subjective overall happiness after COVID-19. Our calculations ascertained that slightly over half of the women in our sample (around 53\%) rated themselves as happy. One can possibly argue that the happiness of women while staying at home and being able to spend more time with family should have been increased but we observe around $47 \%$ of women reported otherwise. Their happiness after COVID-19 was found to be affected by the emotional violence that they face during COVID-19 related lockdown. Their anxiety, lesser decision making, lesser education, and living in a rural area are making them less happy during COVID-19 related lockdown. As it is evident from the debate and our findings that the role of gender is extremely important even during the COVID-19 related lockdown. Therefore, policymaking institutions should consider the mediating role of gender in relevant policymaking. A house is a women domain in the context of Pakistan, where she is mainly responsible for taking care of children and doing household chores. The Government should make policies reaching out to the women lockdown in their house, ensuring their health, safety, and psychological wellbeing. Empowering women can increase the effectiveness of the 493 policies and women can play an important role during these times. Empowered women 
494 affect the lives of their families and children as they have more autonomy in decision 495 making (Ewerling et al. 2017).

496 The study is important in the context of happiness and violence inflicted on women during 497 the lockdown and provides the basis to improve the pandemic response policy. The 498 authors do acknowledge the intrinsic limitations of the current study at this point. First of 499 all, due to the lockdown situation, we had to rely on the online surveying approach, which 500 might have some issues (i.e., inability to reach challenging population such as population 501 living in remote areas and the majority of those women without technology awareness). 502 Yet, this study revealed the vulnerability of women during lockdown staying at home. The 503 irony is women are staying at home to be safe, but they are not safe at their homes from 504 violence. This study conducted in Pakistan provokes the need for similar investigations in 505 other countries where the stereotypical role of women is enforced, and gender equity is 506 not ensured.

507 Factually, violence has affected the significant proportion of the population during the 508 COVID-19 related lockdown. It threatens the lives and physical and mental health of 509 people, overburdens health systems, undermines human capital formation, and slows 510 economic and social development. Thus, one can argue that violence is predictable and 511 therefore preventable. There are many other reasons which are extremely important to 512 prevent the domestic violence for example no domestic violence may increase the 513 subjective happiness and in turn higher productivity of women at work. Hence, preventing 514 domestic violence is not only important from human rights perspective but it can also 515 enhance the economic development and mental health of population. Prevention policies 516 can be achieved through effective policing, strict legislation against violence, and through 517 education.

518

519

520

521

522

523 524

Bland, JM., \& Altman, DG. 1997. Statistics notes: Cronbach's alpha. Bristish Medical Journal 314(7080): 570-572. Available at 
525

526

527

528

529

530

531

532

533

534

535

536

537

538

539

540

541

542

543

544

545

546

547

548

549

550

551

552

553

554

555

556

557

558

559

560

https://www.ncbi.nlm.nih.gov/pmc/articles/PMC2126061/pdf/9055718.pdf (accessed May 2020).

Brooks, SK., Webster, RK., Smith, LE., Woodland, L., Wessely, S., Greenberg, N., \& Rubin, G. J. 2020. The psychological impact of quarantine and how to reduce it: rapid review of the evidence. The Lancet. 395: 912-920.

Chinni, M. (2014). Subjective Happiness Scale. Encyclopedia of Quality of Life and Well-Being Research 6420-6423. Available at https://doi.org/10.1007/978-94-007-0753-5 2898 (accessed May 2020).

de Paz, C., Muller, M., Munoz Boudet, AM., \& Gaddis, I. 2020. Gender Dimensions of the COVID-19 Pandemic. Available at https://openknowledge.worldbank.org/bitstream/handle/10986/33622/GenderDimensions-of-the-COVID-19-Pandemic.pdf?sequence=1 (accessed May 2020)..

Diener, E., \& Seligman, M. E. 2002. Very happy people. Psychological science 13(1): 81-84.

Ewerling, F., Lynch, JW., Victora, C. G., Van EA., Tyszler, M., \& Barros, AJ. 2017. The SWPER index for women's empowerment in Africa: development and validation of an index based on survey data. The Lancet Global Health 5(9): e916-e923.

Fletcher, R. 2013. Practical methods of optimization. New York: John Wiley \& Sons,

García-Moreno, C., Jansen, H., Ellsberg, M., Heise, L., \& Watts, C. 2005. WHO multi-country study on women's health and domestic violence against women. Available at https://www.who.int/reproductivehealth/publications/violence/24159358X/en/ (accessed may 2020)

Gibbs, A., Dunkle, K., Ramsoomar, L., Willan, S., Jama Shai, N., Chatterji, S., Naved, R., \& Jewkes, R. 2020. New learnings on drivers of men's physical and/or sexual violence against their female partners, and women's experiences of this, and the implications for prevention interventions. Global health action 13(1):1739845. DOI: $10.1080 / 16549716.2020 .1739845$

OCHA Pakistan. 2020. OCHA Pakista: COVID-19 Portal. Available at http://pakresponse.info/COVID19-Portal/_(accessed May 2020)

Peterman, A., Potts, A., O’Donnell, M., Thompson, K., Shah, N., Oertelt-Prigione, S., \& Van Gelder, N. 2020. Pandemics and violence against women and children. Center for Global Development Working Paper, 528. Available at https:/www.un.org/sexualviolenceinconflict/wpcontent/uploads/2020/05/press/pandemics-and-violence-against-women-andchildren/pandemics-and-vawg-april2.pdf (accessed May 2020).

Pfitzner, N., Fitz-Gibbon, K., \& True, J. 2020. Responding to the 'shadow pandemic': practitioner views on the nature of and responses to violence against women in Victoria, 
561

562

563

564

565

566

567

568

569

570

571

572

573

574

575

576

577

578

579

580

581

582

583

584

585

586

587

588

589

590

591

592

593

594

595

Australia during the COVID-19 restrictions. Available at https://doi.org/10.26180/5ed9d5198497c (accessed May 2020).

Ravindran, S., \& Shah, M. 2020. Unintended consequences of lockdowns: Covid-19 and the shadow pandemic. NBER Working Papers 27562, National Bureau of Economic Research, Inc. Avaialble at http://www.nber.org/papers/w27562.pdf (accessed May 2020).

Sacket, PR., Larson, JR, 1990 Research strategies and tactics in industrial and organizational psychology In Dunnette, MD., \& Hough, LM. (Eds.), Handbook of industrial and organizational psychology. (2nd ed.) Vol. 1. Chicago, IL: Rand McNally: 419-489

Safdar, M., \& Yasmin Alvi, M. 2020. COVID-19: A Threat to Educated Muslim Women's Negotiated Identity in Pakistan. Gender, Work \& Organization. Avaialable at https://doi.org/10.1111/gwao.12457 (accessed May 2020).

Sánchez, OR., Vale, DB., Rodrigues, L., \& Surita, FG. 2020. Violence against women during the COVID-19 pandemic: An integrative review. International Journal of Gynecology \& Obstetrics DOI: 10.1002/ijgo.13365 (accessed May 2020).

Thomson Reuters Foundation. 2018. Thomson Reuters Foundation annual pol: The world's most dangerous countries for women 2018. Available at https://poll2018.trust.org/_(accessed May 2020)

UNHCR-IDC. 2016. UNHCR-IDC Vulnerability Screening Tool - Identifying and Addressing Vulnerability: A Tool for Asylum and Migration Systems. Avaialble at https://www.unhcr.org/protection/detention/57fe30b14/unhcr-idc-vulnerability-screeningtool-identifying-addressing-vulnerability.html (accessed May 2020).

United Nations. 2020. Policy Brief: The Impact of COVID-19 on Women. Available at https://www.unwomen.org//media/headquarters/attachments/sections/library/publications/2020/policy-brief-theimpact-of-covid-19-on-women-en.pdf?la=en\&vs=1406 (accessed May 2020).

United Nations Office on Drugs and Crime. 2020. Gender and Pandemic: Urgent call for Action Available at https://www.unodc.org/documents/pakistan/Advocacy_Brief_4_Gender_COVID-19-Punjab.pdf (accessed May 2020).

United Nations Women. 2020. Violence against women and girls: The shadow pandemic. Available at https://www.unwomen.org/en/news/stories/2020/4/statement-ed-phumzileviolence-against-women-during-pandemic_(accessed May 2020).

Vázquez JJ, Panadero S, and Rivas E. 2015. Happiness among Poor Women Victims of Intimate Partner Violence in Nicaragua. Social Work in Public Health 30:18-29. DOI: 10.1080/19371918.2014.938389 
597

598

599

600

601

602

603

604

605

606

607

608

609

610

611

612

613

614

615

616

617

618

619

620

621

622

623

624
Wang, C., Pan, R., Wan, X., Tan, Y., Xu, L., Ho, CS., \& Ho, RC. 2020. Immediate psychological responses and associated factors during the initial stage of the 2019 coronavirus disease (COVID-19) epidemic among the general population in china. International Journal of Environmental Research Public Health 17(5): 1729. Available at https://doi.org/10.3390/ijerph17051729 (accessed May 2020).

Warraich, S. 2020. Locked down and vulnerable. The News on Sunday. Avaiable at https://www.thenews.com.pk/tns/detail/678152-locked-down-and-vulnerable (accessed May 2020).

Wenham, C., Smith, J., \& Morgan, R. 2020. COVID-19: the gendered impacts of the outbreak. The Lancet, 395(10227): 846-848.

World Bank. 2020. COVID-19 Coronavirus response World Bank Gender: Guidance for health Covid-19 (coronavirus) response projects. Available at http://pubdocs.worldbank.org/en/425301587156203830/Gender-in-HNP-COVID-19response-4-17-20-external.pdf (accessed May 2020).

World Health Organization. 2005. WHO multi-country study on women's health and domestic violence against women: Initial results on prevalence, health outcomes and women's responses. World Health Organization. Available at https://www.who.int/reproductivehealth/publications/violence/24159358X/en/ (accessed May 2020).

Wu, W., Zheng, J., \& Fang, Q. 2020. How a typhoon event transforms public risk perception of climate change: A study in China. Journal of Cleaner Production 121163. DOI: 10.1016/j.jclepro.2020.121163

Zhang, S. X., Wang, Y., Rauch, A., \& Wei, F. 2020. Health, distress, and life satisfaction of people one-month into COVID-19 outbreak in China. medRxiv. DOI: $10.1101 / 2020.03 .13 .20034496$ 
Table $\mathbf{1}$ (on next page)

Descriptive statistics 
1

2

\begin{tabular}{lccc}
\hline Variables & Range & Mean & $\begin{array}{c}\text { Std. } \\
\text { Deviation }\end{array}$ \\
\hline Woman age & $20-72$ & 37.54 & 10.589 \\
Husband's age & $22-79$ & 41.86 & 11.443 \\
Woman's years of schooling & $0-22$ & 14.21 & 4.018 \\
Husband's years of schooling & $0-20$ & 9.33 & 5.129 \\
Father's years of schooling & $0-22$ & 11.97 & 5.187 \\
Mother's years of schooling & $0-22$ & 15.04 & 4.001 \\
Years of marriage & $1-46$ & 13.94 & 10.698 \\
Number of children & $0-8$ & 2.21 & 1.555 \\
Area & & &
\end{tabular}

Employment status

Family setting

Relationship with husband

Income adequacy

Feel empowered before COVID-19

\section{Table 1: Descriptive statistics}

Urban (325)

Rural (64)

Full time working (332)

Part time working (16)

Unemployed (10)

Not working (31)

Extended family (98)

Multiple family (45)

Nuclear family (246)

Very poor (29)

Poor (23)

Neutral (48)

Good (99)

Very good (190)

Strongly disagree (28)

Disagree (64)

Neutral (69)

Agree (155)

Strongly agree (73)

Not very empowered (19)

Not empowered (25)

Slightly not empowered (36)

Neutral (103)

Slightly empowered (85)

Empowered (72)

Very empowered (49) 
Say in social distancing decision

Feel anxiety

Feel empowered when husband is around

Childcare

Violence

Psychological violence

Access to personal protection equipment

Medical insurance

Decision making
Strongly disagree (36)

Disagree (22)

Neutral (93)

Agree (125)

Strongly agree (113)

Strongly disagree (28)

Disagree (84)

Neutral (72)

Agree (137)

Strongly agree (68)

Strongly disagree (47)

Disagree (47)

Neutral (81)

Agree (115)

Strongly agree (99)

Husband alone (10)

Woman herself (63)

Others (44)

Together (woman and her husband)

(72)

Strongly disagree (93)

Disagree (55)

Neutral (108)

Agree (68)

Strongly agree (65)

Yes (252)

No (137)

Yes (133)

No (256)

Yes (287)

No (102)

Yes (131)

No (258)

Yes (302)

No (87) 
Happiness

Not very happy (42)

Not happy (38)

Slightly not happy (40)

Neutral (57)

Slightly happy (91)

Happy (69)

Very happy (52)

Number of observations

3 Source: Author's calculations

4 
Table 2 (on next page)

Assessment of the best-fitted model for the number of violence 
Table 2: Assessment of the best-fitted model for the number of violence

\begin{tabular}{ccccc}
\hline Parameters & Poisson & Negative Binomial & ZIP & ZINB \\
\hline Location & $3.90(0.10)$ & $3.90(0.56)$ & $2.41(0.03)$ & $2.13(0.15)$ \\
Dispersion & - & $0.13(0.01)$ & - & $0.49(0.27)$ \\
Zero-inflation & - & - & $0.61(0.11)$ & $0.15(0.22)$ \\
\hline Log likelihood & -2872.50 & -712.15 & -1539.66 & $\mathbf{- 7 0 7 . 0 8}$ \\
AIC & 5747.01 & 1428.30 & 3083.31 & $\mathbf{1 4 2 0 . 1 6}$ \\
BIC & 5750.97 & 1436.22 & 3091.24 & $\mathbf{1 4 3 2 . 0 5}$ \\
\hline
\end{tabular}

2

3 


\section{Table 3 (on next page)}

The zero-inflated Negative Binomial regression model for the number of violence 
Table 3: The zero-inflated Negative Binomial regression model for the number of violence

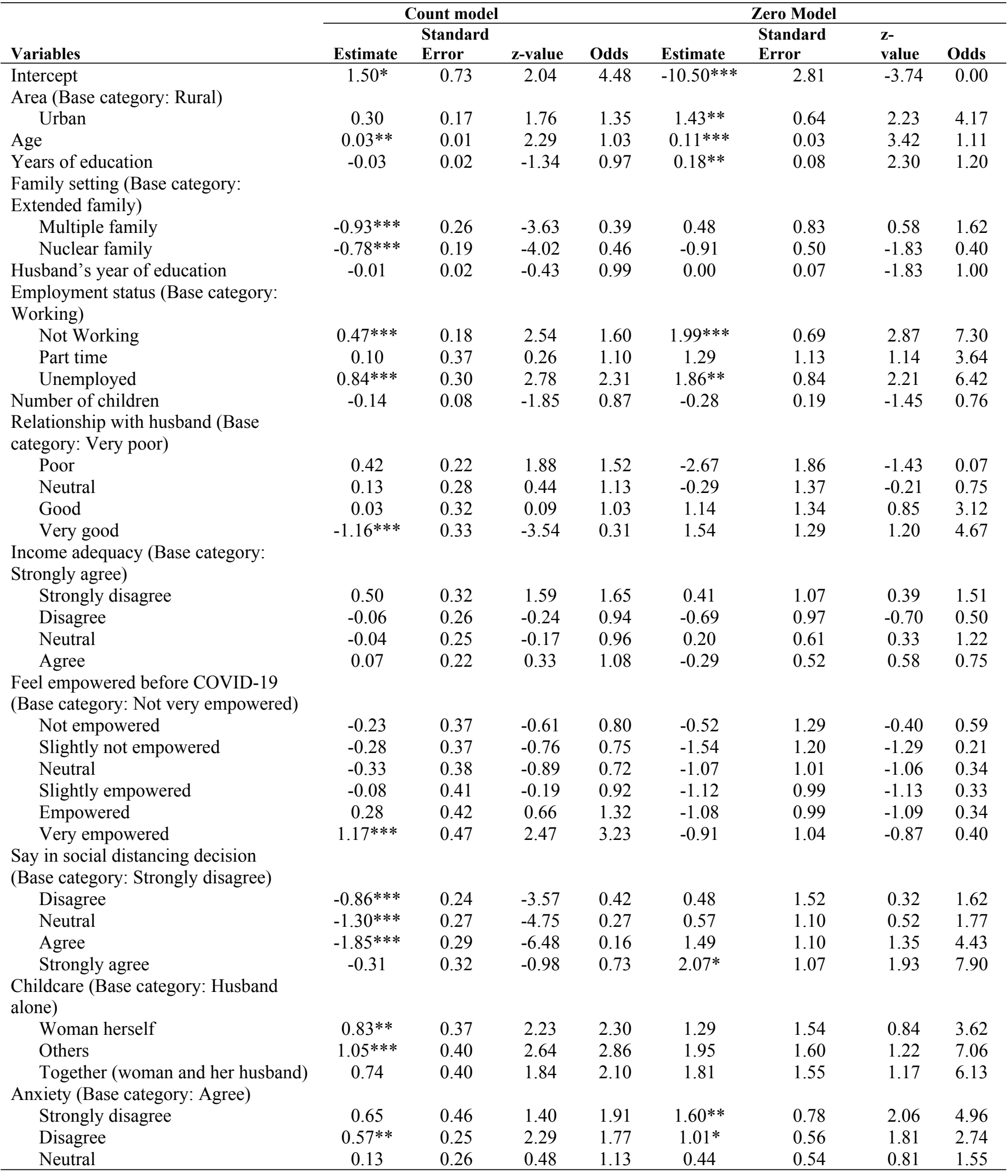




\begin{tabular}{lcccccccc}
\hline $\begin{array}{l}\text { Strongly agree } \\
\text { Feel empowered when husband is } \\
\text { around }\end{array}$ & -0.20 & 0.18 & -1.09 & 0.82 & $-1.18^{*}$ & 0.69 & -1.71 & 0.31 \\
(Base category: Agree) & & & & & & & & \\
$\quad$ & & & & & & \\
$\quad$ Strongly disagree & $1.12^{* * *}$ & 0.29 & 3.82 & 3.06 & 0.52 & 0.89 & 0.59 & 1.69 \\
$\quad$ Disagree & $0.86^{* * *}$ & 0.27 & 3.23 & 2.36 & -0.22 & 0.67 & -0.33 & 0.80 \\
$\quad$ Neutral & $0.48^{* *}$ & 0.24 & 1.99 & 1.61 & 0.08 & 0.53 & 0.15 & 1.08 \\
$\quad$ Strongly agree & -0.11 & 0.29 & -0.38 & 0.90 & -0.07 & 0.55 & -0.13 & 0.93 \\
Log(theta) & $1.30^{* * *}$ & 0.22 & 5.90 & 3.66 & & & & \\
\hline
\end{tabular}

2

3 Note: $*=$ p-value $<0.1, * *=$ p-value $<0.05, * * *=$ p-value $<0.01$

4 Odds $=\exp ($ estimate $)$

5 
Table 4 (on next page)

The multinomial logistic regression model for the happiness 


\begin{tabular}{|c|c|c|c|c|c|c|}
\hline \multirow{2}{*}{ VARIABLES } & \multicolumn{6}{|c|}{ Models } \\
\hline & (2) & (3) & (4) & (5) & (6) & (7) \\
\hline \multicolumn{7}{|l|}{ Area (Base category: Rural) } \\
\hline Urban & $\begin{array}{c}4.32 * * \\
(1.15-16.21)\end{array}$ & $\begin{array}{c}1.74 \\
(0.46-6.56)\end{array}$ & $\begin{array}{c}5.05^{* *} \\
(1.03-24.87)\end{array}$ & $\begin{array}{c}3.56^{*} \\
(0.94-13.47)\end{array}$ & $\begin{array}{c}2.41 \\
(0.59-9.76)\end{array}$ & $\begin{array}{c}2.44 \\
(0.53-11.19)\end{array}$ \\
\hline Age & $\begin{array}{c}0.98 \\
(0.92-1.04)\end{array}$ & $\begin{array}{c}1.01 \\
(0.96-1.07)\end{array}$ & $\begin{array}{c}0.99 \\
(0.94-1.05)\end{array}$ & $\begin{array}{c}0.98 \\
(0.93-1.04)\end{array}$ & $\begin{array}{c}1.00 \\
(0.94-1.05)\end{array}$ & $\begin{array}{c}0.94 * * \\
(0.89-1.00)\end{array}$ \\
\hline Years of schooling & $\begin{array}{c}1.15 \\
(0.96-1.38)\end{array}$ & $\begin{array}{c}1.01 \\
(0.85-1.21)\end{array}$ & $\begin{array}{c}1.19^{*} \\
(0.99-1.43)\end{array}$ & $\begin{array}{c}1.16^{*} \\
(0.98-1.37)\end{array}$ & $\begin{array}{c}1.22 * * \\
(1.02-1.47)\end{array}$ & $\begin{array}{c}1.12 \\
(0.92-1.37)\end{array}$ \\
\hline \multicolumn{7}{|c|}{$\begin{array}{l}\text { Family setting (Base category: Extended } \\
\text { family) }\end{array}$} \\
\hline Multiple family & $\begin{array}{c}1.26 \\
(0.20-7.84)\end{array}$ & $\begin{array}{c}0.41 \\
(0.03-5.45)\end{array}$ & $\begin{array}{c}2.34 \\
(0.35-15.74)\end{array}$ & $\begin{array}{c}3.34 \\
(0.53-21.11)\end{array}$ & $\begin{array}{c}1.01 \\
(0.12-8.50)\end{array}$ & $\begin{array}{c}3.47 \\
(0.44-27.05)\end{array}$ \\
\hline Nuclear family & $\begin{array}{c}1.60 \\
(0.42-6.04)\end{array}$ & $\begin{array}{c}1.98 \\
(0.55-7.13)\end{array}$ & $\begin{array}{c}1.73 \\
(0.47-6.40)\end{array}$ & $\begin{array}{c}3.14^{*} \\
(0.92-10.74)\end{array}$ & $\begin{array}{c}2.52 \\
(0.71-8.93)\end{array}$ & $\begin{array}{c}3.46^{*} \\
(0.87-13.68)\end{array}$ \\
\hline Husband's years of schooling & $\begin{array}{c}0.88 \\
(0.75-1.04)\end{array}$ & $\begin{array}{c}1.12 \\
(0.93-1.36)\end{array}$ & $\begin{array}{c}0.93 \\
(0.78-1.12)\end{array}$ & $\begin{array}{c}1.02 \\
(0.87-1.20)\end{array}$ & $\begin{array}{c}1.09 \\
(0.91-1.30)\end{array}$ & $\begin{array}{c}1.07 \\
(0.88-1.30)\end{array}$ \\
\hline \multicolumn{7}{|c|}{ Income adequacy (Base category: Agree) } \\
\hline Strongly disagree & $\begin{array}{c}0.17^{*} \\
(0.02-1.36)\end{array}$ & $\begin{array}{c}0.33 \\
(0.02-4.53)\end{array}$ & $\begin{array}{c}0.50 \\
(0.03-8.53)\end{array}$ & $\begin{array}{c}0.56 \\
(0.06-5.16)\end{array}$ & $\begin{array}{c}0.21 \\
(0.01-3.25)\end{array}$ & $\begin{array}{c}2.46 \\
(0.24-24.69)\end{array}$ \\
\hline Disagree & $\begin{array}{c}0.44 \\
(0.11-1.76)\end{array}$ & $\begin{array}{c}0.24 * \\
(0.05-1.23)\end{array}$ & $\begin{array}{c}1.02 \\
(0.23-4.53)\end{array}$ & $\begin{array}{c}0.41 \\
(0.10-1.71)\end{array}$ & $\begin{array}{c}0.22 * \\
(0.04-1.09)\end{array}$ & $\begin{array}{c}0.65 \\
(0.10-4.06)\end{array}$ \\
\hline Neutral & $\begin{array}{c}0.23 \\
(0.04-1.46)\end{array}$ & $\begin{array}{c}1.10 \\
(0.25-4.84)\end{array}$ & $\begin{array}{c}1.27 \\
(0.29-5.67)\end{array}$ & $\begin{array}{c}0.40 \\
(0.09-1.71)\end{array}$ & $\begin{array}{c}0.13^{* *} \\
(0.03-0.63)\end{array}$ & $\begin{array}{c}0.72 \\
(0.14-3.71)\end{array}$ \\
\hline Strongly agree & $\begin{array}{c}1.48 \\
(0.17-12.65)\end{array}$ & $\begin{array}{c}5.60 \\
(0.70- \\
44.58)\end{array}$ & $\begin{array}{c}4.15 \\
(0.50-34.60)\end{array}$ & $\begin{array}{c}6.84^{*} \\
(0.92-51.15)\end{array}$ & $\begin{array}{c}1.75 \\
(0.22- \\
14.13)\end{array}$ & $\begin{array}{c}12.31^{* *} \\
(1.46-103.70)\end{array}$ \\
\hline \multicolumn{7}{|c|}{$\begin{array}{l}\text { Access to police (Base category: Strongly } \\
\text { disagree) }\end{array}$} \\
\hline Disagree & $\begin{array}{c}3.31 \\
(0.64-17.19)\end{array}$ & $\begin{array}{c}0.66 \\
(0.10-4.26)\end{array}$ & $\begin{array}{c}3.49 \\
(0.54-22.70)\end{array}$ & $\begin{array}{c}1.44 \\
(0.25-8.28)\end{array}$ & $\begin{array}{c}0.50 \\
(0.07-3.66)\end{array}$ & $\begin{array}{c}0.73 \\
(0.08-6.35)\end{array}$ \\
\hline Neutral & $\begin{array}{c}0.94 \\
(0.19-4.75)\end{array}$ & $\begin{array}{c}0.60 \\
(0.12-2.85)\end{array}$ & $\begin{array}{c}2.28 \\
(0.47-11.17)\end{array}$ & $\begin{array}{c}0.93 \\
(0.21-4.02)\end{array}$ & $\begin{array}{c}0.96 \\
(0.21-4.45)\end{array}$ & $\begin{array}{c}0.74 \\
(0.14-3.96)\end{array}$ \\
\hline Agree & $\begin{array}{c}2.84 \\
(0.36-22.15)\end{array}$ & $\begin{array}{l}3.23 \\
(0.45- \\
23.01)\end{array}$ & $\begin{array}{c}8.06^{* *} \\
(1.03-62.83)\end{array}$ & $\begin{array}{c}3.17 \\
(0.46-22.00)\end{array}$ & $\begin{array}{c}3.70 \\
(0.50- \\
27.34)\end{array}$ & $\begin{array}{c}4.67 \\
(0.58-37.84)\end{array}$ \\
\hline Strongly agree & $\begin{array}{c}0.56 \\
(0.09-3.59)\end{array}$ & $\begin{array}{c}0.19 \\
(0.03-1.44)\end{array}$ & $\begin{array}{c}0.56 \\
(0.08-3.82)\end{array}$ & $\begin{array}{c}0.42 \\
(0.08-2.19)\end{array}$ & $\begin{array}{c}0.38 \\
(0.07-2.17)\end{array}$ & $\begin{array}{c}0.35 \\
(0.06-2.11)\end{array}$ \\
\hline \multicolumn{7}{|l|}{ Anxiety (Base category: Agree) } \\
\hline Strongly disagree & $\begin{array}{c}1.09 \\
(0.04-31.35)\end{array}$ & $\begin{array}{c}1.47 \\
(0.05- \\
43.72)\end{array}$ & $\begin{array}{c}2.34 \\
(0.10-54.97)\end{array}$ & $\begin{array}{c}4.56 \\
(0.26-80.85)\end{array}$ & $\begin{array}{l}14.64^{*} \\
(0.82- \\
261.60)\end{array}$ & $\begin{array}{c}16.30 * \\
(0.91-291.60)\end{array}$ \\
\hline Disagree & $\begin{array}{c}0.37 \\
(0.03-3.95)\end{array}$ & $\begin{array}{c}0.58 \\
(0.07-4.97)\end{array}$ & $\begin{array}{c}3.53 \\
(0.53-23.63)\end{array}$ & $\begin{array}{c}4.83^{*} \\
(0.79-29.48)\end{array}$ & $\begin{array}{l}9.81 * * \\
(1.54- \\
62.56)\end{array}$ & $\begin{array}{c}8.50^{* *} \\
(1.23-58.61)\end{array}$ \\
\hline Neutral & $\begin{array}{c}0.18 \\
(0.01-2.76)\end{array}$ & $\begin{array}{c}0.83 \\
(0.12-5.92)\end{array}$ & $\begin{array}{c}2.45 \\
(0.37-16.18)\end{array}$ & $\begin{array}{c}2.56 \\
(0.40-16.25)\end{array}$ & $\begin{array}{c}4.74 \\
(0.72- \\
31.41)\end{array}$ & $\begin{array}{c}3.74 \\
(0.51-27.60)\end{array}$ \\
\hline Strongly agree & $\begin{array}{c}0.14 * * * \\
(0.04-0.52)\end{array}$ & $\begin{array}{c}0.28^{*} \\
(0.07-1.12)\end{array}$ & $\begin{array}{c}0.07 * * * \\
(0.01-0.35)\end{array}$ & $\begin{array}{c}0.12 * * * \\
(0.03-0.48)\end{array}$ & $\begin{array}{c}0.09 * * * \\
(0.02-0.51)\end{array}$ & $\begin{array}{c}0.12 * * \\
(0.02-0.73)\end{array}$ \\
\hline \multicolumn{7}{|c|}{$\begin{array}{l}\text { Feel empowered when husband is around } \\
\text { (Base category: Agree) }\end{array}$} \\
\hline Strongly disagree & $\begin{array}{c}1.51 \\
(0.22-10.19)\end{array}$ & $\begin{array}{c}0.35 \\
(0.05-2.51)\end{array}$ & $\begin{array}{c}0.00 \\
(0.00-.)\end{array}$ & $\begin{array}{c}0.06 * * * \\
(0.01-0.45)\end{array}$ & $\begin{array}{c}0.12 * * \\
(0.02-0.91)\end{array}$ & $\begin{array}{c}0.06^{* *} \\
(0.01-0.56)\end{array}$ \\
\hline
\end{tabular}




\begin{tabular}{|c|c|c|c|c|c|c|}
\hline Disagree & $\begin{array}{c}3.47 \\
(0.50-24.01)\end{array}$ & $\begin{array}{c}2.11 \\
(0.30- \\
14.78)\end{array}$ & $\begin{array}{c}1.56 \\
(0.24-10.14)\end{array}$ & $\begin{array}{c}0.65 \\
(0.10-4.23)\end{array}$ & $\begin{array}{c}0.97 \\
(0.14-6.75)\end{array}$ & $\begin{array}{c}0.60 \\
(0.07-5.58)\end{array}$ \\
\hline Neutral & $\begin{array}{c}4.65 \\
(0.70-30.88)\end{array}$ & $\begin{array}{c}2.75 \\
(0.46- \\
16.35)\end{array}$ & $\begin{array}{c}2.07 \\
(0.37-11.47)\end{array}$ & $\begin{array}{c}0.91 \\
(0.17-4.87)\end{array}$ & $\begin{array}{c}0.81 \\
(0.14-4.73)\end{array}$ & $\begin{array}{c}0.54 \\
(0.08-3.74)\end{array}$ \\
\hline Strongly agree & $\begin{array}{c}2.04 \\
(0.27-15.11)\end{array}$ & $\begin{array}{c}1.24 \\
(0.20-7.86)\end{array}$ & $\begin{array}{c}0.54 \\
(0.09-3.26)\end{array}$ & $\begin{array}{c}0.92 \\
(0.17-4.90)\end{array}$ & $\begin{array}{c}1.05 \\
(0.19-5.93)\end{array}$ & $\begin{array}{c}1.25 \\
(0.21-7.43)\end{array}$ \\
\hline \multicolumn{7}{|l|}{$\begin{array}{l}\text { ychological violence (Base category: } \\
\text { o) }\end{array}$} \\
\hline . & $\begin{array}{c}1.11 \\
(0.29-4.29)\end{array}$ & $\begin{array}{c}1.40 \\
(0.38-5.18)\end{array}$ & $\begin{array}{c}0.67 \\
(0.18-2.51)\end{array}$ & $\begin{array}{c}0.44 \\
(0.13-1.55)\end{array}$ & $\begin{array}{c}0.48 \\
(0.13-1.83)\end{array}$ & $\begin{array}{c}0.10 * * * \\
(0.02-0.57)\end{array}$ \\
\hline \multicolumn{7}{|l|}{$\begin{array}{l}\text { ccess to personal protection equipment } \\
\text { 3ase category: No) }\end{array}$} \\
\hline Yes & $\begin{array}{c}0.92 \\
(0.24-3.59)\end{array}$ & $\begin{array}{c}1.90 \\
(0.39-9.40)\end{array}$ & $\begin{array}{c}2.67 \\
(0.39-18.15)\end{array}$ & $\begin{array}{c}0.53 \\
(0.13-2.21)\end{array}$ & $\begin{array}{c}0.62 \\
(0.12-3.10)\end{array}$ & $\begin{array}{c}0.45 \\
(0.08-2.50)\end{array}$ \\
\hline edical insurance (Base category: No) & & & & & & \\
\hline Yes & $\begin{array}{c}0.29^{*} \\
(0.08-1.01)\end{array}$ & $\begin{array}{c}0.38 \\
(0.11-1.28)\end{array}$ & $\begin{array}{c}0.48 \\
(0.15-1.56)\end{array}$ & $\begin{array}{c}0.42 \\
(0.14-1.30)\end{array}$ & $\begin{array}{c}0.39 \\
(0.12-1.26)\end{array}$ & $\begin{array}{c}0.55 \\
(0.16-1.87)\end{array}$ \\
\hline ecision making (Base category: No) & 1.48 & 0.95 & $2.79 * *$ & $2.05^{*}$ & $2.53^{* *}$ & $2.90 * * *$ \\
\hline & $(0.67-3.27)$ & $(0.42-2.14)$ & $(1.26-6.17)$ & $(1.00-4.20)$ & $(1.19-5.38)$ & $(1.33-6.35)$ \\
\hline onstant & $\begin{array}{c}0.49 \\
(0.01-44.03)\end{array}$ & $\begin{array}{c}0.09 \\
(0.00-6.88)\end{array}$ & $\begin{array}{c}0.00 * * \\
(0.00-0.39)\end{array}$ & $\begin{array}{c}0.09 \\
(0.00-4.67)\end{array}$ & $\begin{array}{c}0.01^{* *} \\
(0.00-0.50)\end{array}$ & $\begin{array}{c}0.05 \\
(0.00-5.50)\end{array}$ \\
\hline glikelihood & $-540.31 * * *$ & & & & & \\
\hline eudo R-square & 0.27 & & & & & \\
\hline est of parallel lines (loglikelihhod) ${ }^{1}$ & $100.90^{* * *}$ & & & & & \\
\hline bservations & 389 & 389 & 389 & 389 & 389 & 389 \\
\hline
\end{tabular}

Note: $*=$ p-value $<0.1, * *=$ p-value $<0.05, * * *=$ p-value $<0.01$

Relative risk ratio is shown for each variable along with standard errors in brackets.

The multinomial logistic regression shows model for not happy (2), slightly not happy (3), neither happy nor unhappy (4), slightly happy (5), happy (6), very happy (7). Not very happy (1) is the base outcome.

RRR: Relative risk ratio, SE: Standard error

${ }^{1}$ We tried to fit ordinal logit but the assumption of parallel lines was violated which suggested the use of multinomial logistic regression. 